\title{
Derechos humanos y democracia en la complejidad latinoamericana
}

\section{POR LUIS MELIANTE GARCÉ $(*)$}

\begin{abstract}
Sumario: I. Los derechos llamados humanos: cuestión polifacética. Una mirada a Latinoamérica.- II. Capitalismo transnacional, globalización y derechos humanos en Latinoamérica.- III. La cuestión "sujeto", la "subjetividad" y los derechos mirados en clave latinoamericana.- IV. Democracia y derechos humanos. ¿Qué democracia?- V. La situación de Uruguay. Breves conclusiones.- VI. Bibliografía.
\end{abstract}

Resumen: en el texto que sigue se aborda desde una perspectiva crítica y en clave latinoamericana, uno de los aspectos más relevantes de las sociedades complejas contemporáneas del continente, como lo es el relativo a los denominados - entre tantas otras formas- "derechos humanos", con una breve referencia particularizada a Uruguay, avanzado el siglo XXI. Se analiza en ese marco la viabilidad de la emergencia de un concepto de "humanismo" y de "sujeto", que sean propios para tal contexto. Si bien el planteo reclama perspectivas de diversa índole - políticas, jurídicas, sociales, culturales- se prioriza aquí su contenido político que desemboca finalmente en el resultado que se propone, vinculándolo con el concepto de "democracia radical". Ello convoca una aproximación a un tema que durante largo tiempo preocupó a la filosofía jurídica, hoy de alguna manera resignado por ella, como es la relación entre dos importantes categorías: Derecho y Poder.

Palabras claves: derechos humanos - Latinoamérica - democracia radical humanismo - sujeto

\section{Human rights and Democracy in Latin American complexity}

Abstract: in the text that follows, it is approached from a critical perspective and in a Latin American key, one of the most relevant aspects of contemporary complex societies in the continent, such as the one related to the so-called "human rights",

(*) Prof. Adjunto Efectivo Filosofía y Teoría General del Derecho, Facultad de Derecho, Universidad de la República, Uruguay. Prof. Titular Filosofía y Teoría General del Derecho y de Escritura Académica III, Facultad de Derecho, Universidad del Centro Latinoamericano de Economía Humana. Prof. Teoría General del Derecho, Maestría de Derecho de Daños, Núcleo de Derecho Civil, Facultad de Derecho, Universidad de la República, Uruguay. 
among many other forms, with a brief reference particularized to Uruguay, advanced SXXI. The feasibility of the emergence of a concept of "humanism" and of "subject" that are specific to such a context is analyzed in this framework. Although the proposal calls for different perspectives - political, legal, social, cultural-its political content is prioritized here, which ultimately leads to the result that is proposed, linking it to the concept of "radical democracy". This summons an approach to a topic that for a long time worried legal philosophy, today somehow resigned to it, as is the relationship between two important categories: Law and Power.

Keywords: human rights - Latin America - radical democracy - humanism - subject

\section{Los derechos llamados humanos: cuestión polifacética. Una mirada a Latinoamérica}

Debe efectuarse la sana prevención de que las ideas más sólidas que pueda tener este apartado encuentran su relación más profunda en otros tantos textos, propios y ajenos, por lo que, de manera, debe excluirse al autor como un iniciador de la discursividad, sino más, aceptarle como un verdadero bricoleur, habida cuenta que en un tema como el que se propone, ha de renunciarse a la creación absoluta, ex nihilo (Maurel-Indart, 2014). No obstante, nada de lo que aquí se expone carece de la convicción y énfasis necesarios para que pueda percibirse un fuerte intento de descubrir nuevos sentidos a lo ya dicho, o por lo menos la búsqueda de amplitud de aquellos que ya se aportaron.

Se prescindirá de referencias históricas relativas al nacimiento de los llamados derechos humanos, sin perjuicio de que resulta procedente especificar tan solo que este aspecto, como se sabe, no está desligado del nacimiento del concepto jurídico-político de Estado de Derecho, que se va gestando, a partir de las revoluciones inglesa de 1688, norteamericana de 1787 y francesa de 1789.

Lo anterior es el contexto adecuado para mencionar someramente otro aspecto. En efecto, la posibilidad de analizar los fundamentos de los derechos humanos, cuya nomenclatura y vigencia puede situarse a partir de las históricas revoluciones aludidas, lleva a la necesidad de aclarar cuestiones terminológicas y especialmente su categorización como "humanos" en donde, o se acepta que tales derechos tienen una fuente textual o normativa emanada de una autoridad legítima, o su fuente es otra. Como es fácil inferir, en este tema se entremezclan cuestiones filosóficas, ideológicas y lingüísticas, y surgen posiciones absolutamente contradictorias en su análisis y consideración, con una oferta de posibilidades que resultan ahora y para esta ocasión, claramente inabordables. 
De tal manera, afirmar que el tema de los denominados derechos humanos es una cuestión polifacética, además de lo expuesto, implica instalar la misma en un ámbito en el que su debate se ha incrementado notoriamente en la realidad latinoamericana actual, más allá de las posibles discrepancias en su fundamento y denominación, respecto a lo que no existe aún uniformidad de criterios (derechos humanos, derechos fundamentales, derechos individuales, derechos naturales, etc.) y en donde deberán tenerse en cuenta necesariamente los aspectos simbólicos que conlleva la referida creación.

La vida sociopolítica actual que transcurre en el horizonte cultural latinoamericano (Cobos, 1995; Meliante, 2014)(1) parece demostrar sin intermitencias que el tema de los derechos humanos, incluso dejando de lado su génesis histórica, como se ha expresado, constituye un ámbito de especulaciones, debates serios, juicios críticos razonables y de los que no lo son, que hace que se mantenga su vigencia en forma indiscutible (Meliante, 2006, p. 16). Cuando existen circunstancias políticas, jurídicas y sociales, que son consecuencia de la gestación e instalación de regímenes autoritarios, de los que Latinoamérica tiene experiencia sobrada, sobre todo a través de sus décadas infames (Bruschera, 1986) y algunas recidivas actuales, está absolutamente justificado que nazcan reivindicaciones basadas en la necesidad de vigencia de los llamados derechos humanos, en la medida que esos episodios, conculcan y laceran el sistema general de libertades y derechos.

Resulta notorio que, en el presente, en el marco de las formaciones sociales que integran tal horizonte cultural latinoamericano, y desde sus respectivas peculiaridades, aparecen aún en forma recurrente tanto la invocación, como a su vez la demanda de vigencia de los derechos humanos. En este contexto, emerge con cierta notoriedad la pretensión de realización plena de los llamados "derechos sociales", que redimensionados se han integrado a aquella categoría más amplia de los derechos humanos en forma explícita, siempre y cuando no se entienda que, por inherencia, pertenecían en forma propia a la misma.

Entre reclamos y divergencias sobre su fuente, nomenclatura y vigencia, será tesis de este trabajo, sostener que los derechos humanos constituyen un fenómeno propio de la actividad social del hombre en donde se conjugan todos los aspectos posibles de la vida humana y que, según sean las condiciones sociales en que se desarrolle la misma, pueden emerger a través de reivindicaciones concretas que se consuman ya en lo social, ya en lo jurídico, ya en lo económico, ya en lo

(1) El concepto de horizonte cultural es una categoría de análisis creada, con definiciones propias, lingüísticas, culturales propiamente en el mayor sentido, sociales, incluso también antropológicas, etc. Sirve para diferenciar en función de esas definiciones, por ejemplo, a gran parte geopolítica de Latinoamérica (el horizonte cultural latinoamericano), que es diferente al horizonte cultural norteamericano, por ejemplo. 
político, ya en lo cultural o lo ecológico, sin perjuicio de los cruces de fronteras que puede haber de una a otra de estas categorías. En suma, los derechos humanos se relacionan así con todos los ámbitos que conforman la praxis humana.

De esta manera, como ya se adelantara, en determinadas sociedades con regímenes políticos en donde campee el autoritarismo cualquiera sea su génesis y signo, estos derechos suelen aparecer de la mano de reivindicaciones relativas a la libertad, a la necesidad de inviolabilidad de la dignidad personal, a la libertad de opinión, a las libertades políticas, etc. Otras veces en sociedades dependientes, integrantes del capitalismo periférico como son en su mayoría las latinoamericanas, las necesidades esenciales de la vida promueven a un primer plano los derechos sociales en general, laborales, socioeconómicos y culturales. También la existencia de determinadas patologías sociales como pobreza, enfermedad, hambre, ignorancia, discriminación, olvido de la situación de las poblaciones indígenas,

(...) no solo constituyen violaciones en sí mismas de los derechos humanos, sino que determinan las condiciones materiales que hacen posible la realidad misma (...) invocar en medio de la explotación y la miseria los derechos humanos como una realidad, constituye una forma de hipocresía, un esfuerzo por ocultar y engañar (...) otra manera, es la invocación de un formalismo vacío que se satisface en la mera existencia de los textos jurídicos (...) (Gross Spiell, 2010, p. 11).

\section{Capitalismo transnacional, globalización y derechos humanos en Latinoamérica}

La forma aparentemente circular, pero a la vez linealmente recta - en lo que dice relación con su proclividad de aceptación - que ha asumido la última evolución del capitalismo transnacional que opera a escala mundial y que de manera eufemística se ha autodenominado "globalización", ha impactado fuertemente en Latinoamérica, epicentro generalizado periférico y dependiente de ese fenómeno.

Resulta ser claramente un fenómeno irreversible, respecto al cual no puede saberse a ciencia cierta cuáles son los márgenes de su expansión, ni tampoco las consecuencias que esta conlleva y, menos aún, la dirección que la misma pueda llegar a tomar.

En relación con el mismo, Ulrich Beck ha denominado ideología del globalismo, entendiendo por "globalismo":

(...) aquella concepción según la cual el mercado mundial desaloja o sustituye el quehacer político, es decir (...) (es) la ideología del dominio del mercado mundial o ideología del liberalismo (...) que procede de 
manera monocausal y economicista y reduce la pluridimensionalidad de la globalización a una sola dimensión, la económica (...) destacando (...) el presunto predominio del mercado mundial (...) (1998, p. 27).

Esta cuestión revela así el núcleo ideológico del globalismo, que se da de traste — dice Beck - con una distinción fundamental de la primera modernidad, a saber, la existente entre política y economía. Así, "la tarea esencial de la política que era delimitar bien los marcos jurídicos, sociales y ecológicos dentro de los cuales el quehacer económico es posible y legítimo socialmente, se sustrae así a la vista o se enajena (...)" (Beck, 1998, p. 27).

La profunda alteración provocada por el fenómeno en curso, en la relación Sociedad Internacional - Estado Nacional repercute en lo más profundo de la dinámica intraestatal, dificultando en forma grosera los procesos naturales de integración social que provoca la desestabilización de sectores socioeconómicos y culturales propios de las identidades nacionales; lo que conlleva también un debilitamiento progresivo de la actividad mediadora y política del Estado y repercute sustancialmente en el debilitamiento de la inversión productiva en pos de la inversión financiera, cuyos designios y enclaves, suelen muchas veces ser absolutamente desconocidos y también indescifrables.

La sociedad resultante, que suele calificarse de posmoderna, pese a que la denominación resulta a esta altura anacrónica; también se le ha denominado: "(...) sociedad pos industrial y como sociedad de la información", puesto que "la información es mercadería valiosa, y como tal corre la suerte del intercambio. En esta nueva era, las tecnologías facilitan la creación, distribución y manipulación de la información que - como moneda virtual - es un elemento clave en el desarrollo personal, social, cultural y económico (...)” (Fernández Oliva, 2014, p. 185).

No es ajena a esta idea tampoco, la idea de modernidad líquida manejada por Zigmunt Bauman (Bauman, 2004), quien denominó así a aquel constructo social que, en términos generales, se acomoda a la lógica de mercado impulsada por la globalización asociada a la fase actual de la llamada "posmodernidad", pese a que, como se adelantara, puede discutirse la procedencia actual de tal denominación. En la lógica baumaniana, es éste, un escenario de profundos cambios económicos, sociales, políticos y culturales en general, que arroja a la humanidad a un futuro incierto. El derecho se ve sacudido también por la avasallante movilización que estos cambios provocan.

Es el momento en el que desde algunos centros de poder — a veces ocultos, a veces no- se puja por la desregulación, por la flexibilización y liberalización de los mercados, por la hegemonía del mercado global, por la privatización, por la excesiva ponderación de la responsabilidad individual, por la mitigación de lo 
público. Es también el momento en donde, sin estar desligado de lo anterior, en muchos aspectos de lo social, campean la inestabilidad y la incertidumbre, inclusive jurídica. En suma, un escenario donde prima lo efímero y cambiante.

Injusticia social, desigualdad material, problemas de tipo laboral, delincuencia más violenta y sofisticada, problemas medioambientales, déficits o deteriores en la legitimación y autocomposición democrática de los Estados Nacionales, repercuten riesgosamente en este escenario, en el centro mismo del concepto de derecho, así como asaz, en el propio concepto de Estado de Derecho, no solamente en su sentido más tradicional, sino también en su forma nueva - por lo menos para Latinoamérica-, la del llamado Estado constitucional de derecho. Todo esto, claro está, sin contar otro tipo de problemas que afectan directa y particularmente a algunos países de Europa y a Norteamérica y no precisamente a Latinoamérica - por lo menos directamente- y que de alguna manera se conectan con nuevas tipologías de claros fundamentalismos de sentidos inversos que se retroalimentan en su conflictividad en forma permanente (Meliante, 2018, pp. 1076, 1077).

De tal manera, es inevitable que esta cuestión se inserte en forma necesaria en el campo de los llamados derechos humanos.

En síntesis, pues, en este contexto de capitalismo transnacional enmarcado en los ejes de la globalización (un proceso irreversible, caracterizado por ser la más reciente revolución capitalista, en donde los Estados nacionales, antes claramente independientes, resignan esa condición a través de actores trasnacionales, aspecto que repercute fuertemente también en las formas de distribución del poder), del globalismo (la ideología que lo sustenta, cuyas notas principales se han caracterizado más arriba) y de la globalidad (que se resume en la certeza del hombre contemporáneo y, por ende, de las distintas comunidades, de que hace tiempo que se vive en una sociedad mundial y que la tesis de los espacios cerrados es inviable), resulta necesario preguntarse cuál es el papel que juega el sujeto, en medio de tal maraña.

Hacia esa respuesta se irá en el curso del apartado siguiente.

\section{La cuestión del "sujeto", la "subjetividad" y los derechos humanos mirados en clave latinoamericana}

Yamandú Acosta, connotado investigador uruguayo, afirma que la cuestión del sujeto no es un asunto o un tema más, entre lo que se identifica como "paradigma fuerte de la filosofía latinoamericana", en tanto la propia filosofía latinoamericana, es "un modo de objetivación en la constitución de un sujeto a través de su autoafirmación, auto-conocimiento y auto- reconocimiento (...)” (2008, p. 93). 
El autor identifica como "paradigma fuerte de la filosofía latinoamericana", aquel que se fundamenta y desarrolla en los trabajos del filósofo argentino Arturo Andrés Roig, en el conjunto de su obra filosófica e historiográfica.

En esta filosofía paradigmática que señala Acosta, la identificación del sujeto tiende a superar el utopismo de la modernidad y el antiutopismo nihilista de la posmodernidad, lo que se materializa con la identificación de sujetos empíricos e históricos, individuales y sociales, con una perspectiva realista y pluralista

(...) que en lugar de proponer un modelo de sociedad al modo de la modernidad, o legitimar la sociedad existente como la única posible al modo de la posmodernidad, funcional a la ideología del mercado total, como se viera; lo hace a través de factibilidad y legitimidad, que permiten juzgar tanto acerca de sociedades vigentes como de sociedades futuras, con discernimiento entre sociedades posibles y sociedades imposibles (...) (2008, p. 94).

Se entiende necesario también focalizar el presente análisis en su aspecto resolutivo, que indica la emergencia de un sujeto

(...) que se constituye por el desarrollo de un punto de vista crítico, que no es otro que el de la emancipación humana desde sus condiciones objetivas de existencia, proceso de autoconstitución que supone el desmontaje de las formas de dominación estructurales, sistémicas e institucionales, así como de los discursos de explicación-legitimación que las expresan y acompañan (...) (Acosta, 2008, p. 98).

De tal forma, la perspectiva crítica y emancipatoria como anclaje filosófico en clave latinoamericana, fundamenta un sujeto (sujeto-otro, dice Acosta), que da respuesta a la subjetividad emergente de la modernidad, aun propiamente críticoemancipatorias de la propia modernidad, y también da respuesta a las visiones antiemancipatorias de la posmodernidad, en su lógica de mercado excluyente (Acosta, 2008, p. 99).

Necesariamente la cuestión del sujeto, que aquí meramente se esboza, requiere a su vez la consideración del correlato de una subjetividad, esto es, un modo de pensar y sentir que acompañe al sujeto en sus condiciones objetivas de existencia.

Las ideas que se han expuesto, que como ha señalado acuñan el pensamiento de Roig, que Acosta asume como su discípulo, y en el presente texto se valorizan notoriamente, implican considerar la necesidad de percibir la filosofía latinoamericana como un verdadero "humanismo" (Acosta, 2015, p. 117). 
De tal manera, toman para ello relevancia cuatro categorías que fueron sustento del discurso filosóficamente crítico de Roig, y que son: 1) el a priori antropológico; 2) la idea que traduce el apotegma de Spinoza de que "nada hay más valedero para el hombre que el hombre mismo"; 3) el concepto de Roig de moral de la emergencia, vinculándolo al espíritu del humanismo de nuestra América, y 4) el análisis de un humanismo crítico desde nuestra América.

El "a priori antropológico" acuñado por Roig es, como dice el autor, la categoría analítico-crítico-normativa central para fundamentar la tesis de su pensamiento como un "humanismo crítico desde nuestra América". Esta categoría tiene, además, una doble significación: 1) en ella se sustenta el sentido del pensamiento filosófico de Roig, así como de su intensa y fecunda labor historiográfica, tendiente a desarrollar su pensamiento en sinergia e interlocución - dice Acosta-con comienzos y recomienzos, potenciando precisamente cada nuevo recomienzo, y 2) es, además, en esa relación que se impone la comprensión de la historicidad de todo hombre, un horizonte de comprensión - así lo califica el propio Roig - que nos conduce a revisar la problemática del humanismo (Acosta: 2015, p. 117).

De esta manera, seguramente pueda apreciarse que el humanismo en Roig, culmina consolidándose como una orientación del pensamiento

(...) que coloca al ser humano como lo supremo para el ser humano mismo, orientación con la que puede identificársela modernidad desde sus orientaciones más tempranas, pero Roig lo hace desde un lugar diferente al de la modernidad eurocéntrica de los S XVI a XIX, y también diferente al de la sucedánea norte-céntrica, que impregna los $\mathrm{S}$ XX y XXI (Acosta, 2015, p. 118).

Ese propio, tanto para Roig como para Acosta, hinca sus raíces en un texto que constituye un enclave discursivo paradigmático y que es "Nuestra América", escrito por José Martí en 1891.

El humanismo así percibido, cuya raíz se encuentra en "Nuestra América", implica necesariamente un "nosotros" que se constituye desde la conflictividad, que nunca se perfecciona y transita entre la tensión que provoca la vivencia defectiva de lo tópico y la plenitud de lo utópico (Acosta, 2015, p. 118).

Señala el autor, que este "humanismo crítico" tiene relaciones con el humanismo, con el pensamiento crítico y con la modernidad, y se constituye como se ve, desde un texto principal que es "Nuestra América". Ello implica que, en forma clara, se rechace cualquier tipo nominal de "humanismo", que opere como "anti humanismo" e incluso más cuando "en una perspectiva crítica el humanismo 
dominante, llega a oficiar como discurso legitimador de una lógica de opresión de las periferias dominadas" (Acosta, 2015, p. 119).

Así concebido va más allá de la modernidad euro-norte-céntrica y también se despliega contra ella, pero no como posmodernidad, porque en ésta, el discurso anti-humanista se potencia con su lógica de mercado monocausal, economicista, deslegitimadora de las identidad, nihilista, anti universal y anti emancipadora. Esto porque la posmoderna, como se pudo apreciar en el apartado precedente, es una lógica absolutamente perversa.

El "humanismo nuestro americano", mentado por Roig y que se potencia en el trabajo de Acosta, se transforma en un "humanismo crítico", contra-moderno o trans-moderno al decir del argentino Enrique Dussel (Acosta, 2015, p. 119).

En suma, este "a priori antropológico de Roig", resulta ser político, en el sentido griego de construcción de comunidad, como dice Acosta (2015), pero también en el de construcción de poder, como construcción de un "nosotros" histórico y empírico, que se transforma en subjetividad propiamente, de cuyo concepto se ha dado cuenta líneas antes.

Naturalmente se nutre del "a priori" trascendental mentado por Kant y también continuado por Hegel, pero sucede que en Roig se rompe con esa concepción, es decir, si en Kant, el sujeto trascendental es la condición de validez de todo conocimiento, acción y discernimiento; en Roig, por el contrario, el sujeto se percibe como empírico, históricamente situado y, como tal, es concebido como la condición de posibilidad de un sujeto trascendental, aún como mera hipótesis epistemológica. El sujeto empírico e histórico de Roig, no es el sujeto universal del a priori epistemológico de Kant, ni tampoco el sujeto ontológico metafísico propio del espíritu absoluto hegeliano.

De esta manera, Kant y Hegel, pero más allá de ellos, el sujeto de Roig, es protagonista de un nosotros de identidad, crítico, y profundamente adverso al anti-humanismo, en cualquiera de sus variantes, que provengan de la lógica euro-nortecéntrica (Acosta, 2015, p. 120).

Culmina afirmando Acosta que el texto de Martí se constituye de esta forma, de la mano de Roig, en un verdadero manifiesto, punto crucial en donde se trata de pensar, sentir, y actuar como un "nosotros" que trascienda a nuestra individualidad. Ese lugar es, "Nuestra América" y el "nosotros" filosófico, político, cultural y finalmente humano, somos "nosotros los latinoamericanos", conforme a lo afirmado por Horacio Cerutti-Guldberg e impulsado por el mismo Roig (Acosta, 2015, p. 124). 
De tal manera, "el quiebre de las totalidades opresivas tanto internas como externas "emergencia nacional y emergencia social" (Acosta, 2015, p. 124), por supuesto que con un alcance muy diferente al de la vulgata política que los uruguayos tenemos por costumbre escuchar desde hace un tiempo a esta parte. Ambas resultan inescindibles para una ética universalista que ponga su mirada en los grupos humanos sociales, donde el "nosotros" alcance su máxima expresión.

Como puede apreciarse, proponer un pensar en "nuestra América" y de consuno en nuestra "Latinoamérica" en el sentido ya citado de horizonte cultural, categoría expuesta al comenzar este texto, implica primordialmente visualizar un "nosotros" que se configure social, política y culturalmente para también focalizar las particularidades de un "derecho en y desde Latinoamérica", que presuponga un eje y anclaje central y radical en los derechos humanos, emergentes de un "humanismo crítico nuestro-americano", para aportar así posibles soluciones a las distintas complejidades sociales de ese horizonte cultural.

El pensamiento crítico, sustento filosófico de esta trama constituyente de una racionalidad para Latinoamérica, nutre también su propia variante jurídica, que promueve en otros aspectos en forma precisa, la necesidad del análisis más profundo de la noción de sujeto, categoría que claramente para el derecho resulta primordial.

Hablar de una teoría crítica latinoamericana para el derecho implica la necesidad de comprenderlo como un fenómeno de naturaleza social, alejado de las visiones objetivistas de las ciencias naturales y de las visiones puramente deductivistas de las ciencias formales. Se asume también como un producto histórico de la evolución de las sociedades humanas, constitutivo de la construcción de sentido en la interacción social, se considera que es una práctica social constitutiva de sentido en relación constante con diversas dimensiones sociales; con la economía, con la política, con el poder, con la ideología, con la moral, etc. (Cárcova, 2007).

El pensamiento crítico pretende también desde esta perspectiva jurídica, recategorizar al sujeto otorgándole un lugar de privilegio tanto en lo histórico, como en lo social, lo político, lo ideológico, lo económico, etc.

El derecho es funcional a cada una de esas categorías (histórico, social, político, ideológico, etc.), como éstas lo son al derecho. Confluyen todas y se nutren unas de otras, recíprocamente, lo que supone que ninguna de ellas (lo histórico, lo social, lo político, lo ideológico, lo jurídico, etc.) pueda prescindir de las otras.

Lucía M. Aseff ha expresado que el "sujeto de derecho", categoría jurídica aportada por la modernidad, es: 
Uno de los conceptos fundamentales alrededor del cual se estructura y organiza todo el derecho moderno, como si fuera en realidad preexistente a su interpelación y constitución por las palabras de la ley, no deja de ser una categoría histórica propia de la modernidad, tanto como lo son las cualidades que se le atribuyen ( libertad, autonomía), sin reparar que, como dice Alicia Ruiz, "la humanidad", "la vida humana", "lo humano", "el hombre", no son realidades dadas de una vez y para siempre, sino que son definiciones culturales que adquieren significación en tanto están contextuadas. En todo caso, son conceptos construidos y no dados de antemano, a los que no solo cabe descubrir, sino a los que cabe desmontar para averiguar cómo se han constituido y cómo funcionan (...) (Assef, 1998, p. 27).

Por su parte, Boaventura De Sousa Santos, en su proyecto sobre una pos-modernidad de oposición, establece que

Es necesaria una nueva teoría de la subjetividad que explique el hecho de que nos encontramos en una compleja red de subjetividades que va incrementándose. Más allá de las ruinas del colectivismo social, está emergiendo el colectivismo del "yo". La lucha frente a los monopolios de interpretación debe orientarse de tal forma que lleve a la proliferación de comunidades interpretativas políticas y jurídicas (...) (De Souza Santos, 1989, p. 247).

De esta manera, pensar lo jurídico a partir del derecho en el sentido que se ha expuesto, es pensarlo inicialmente desde los derechos humanos que han encontrado consagración positiva no sólo en tratados y declaraciones internacionales, sino también en las Constituciones de la enorme mayoría de los países con tradición democrática en el mundo entero. Hablar de derechos humanos, entonces, es hablar de democracia, conclusión ésta que parece necesaria y hasta elemental, en cuyo caso, se hace imprescindible precisar el concepto relativo a la misma, aspecto que como se apreciará, se abordará en el apartado siguiente.

\section{Democracia y derechos humanos. ¿Qué democracia?}

Como se tratará de exponer brevemente a continuación(2), la complejidad societaria latinoamericana nacida al pairo de la reconfiguración global acaecida en

(2) Como quedó explicitado en el Resumen introductorio del presente trabajo, el tema principal convocado en el mismo, no es precisamente realizar un estudio exhaustivo de lo que debe entenderse por "democracia radical", por más que tal concepto opere como una variable independiente en relación con los grandes temas sí considerados prioritarios, de los "derechos humanos" así aquel relativo al rescate de los conceptos de "sujeto" y de "subjetividad", para Latinoamérica. De todos 
todas las dimensiones posibles, tal como se ha visto en el apartado II del presente trabajo, ha impulsado un modelo de democracia liberal, que se funda básicamente en la liberalización de la economía y mayormente de los sistemas financieros, a la vez que propende a la contracción de las funciones estatales y a una aceptación del manejo neoconservador del mercado. Tal es el proyecto político del neoliberalismo, que en donde no se ha instalado o reinstalado ya, puja con más vehemencia por recuperar los espacios perdidos que fueran conquistados por algunos gobiernos de corte progresista que se instalaron democráticamente en Latinoamérica al inicio o poco más, de los años 2000 (Mejía Quintana y Jiménez, 2005, p. 14).

Frente a esta alternativa existen distintas perspectivas teóricas de estructuración democrática que van en sentido diferente, y procuran recuperar en forma real el contenido utópico que claramente se expropia en el modelo que pretende imponer el neoliberalismo, así como en forma similar, ocurre con el protagonismo subjetivo que claramente es desplazado en el mismo.

Una de tales posibilidades, es aquella que se ha denominado democracia radical.

En términos generales, parece correcto atribuir a Jürgen Habermas la idea y promoción del concepto de democracia radical. Sin perjuicio de haber desarrollado en varias de sus obras el referido concepto, Habermas expresó en forma contundente: “(...) He escrito mi filosofía del derecho para aclarar a los conservadores, y a los condenados juristas nuestros, tan defensores siempre del Estado, que no se puede mantener el Estado de Derecho, ni tampoco mantenerlo, sin una democracia radical (...)" (1998, p. 11).

modos, al margen de las aproximaciones efectuadas, a los efectos de profundizar el tema, pueden consultarse innumerables textos, entre otros: de Gargarella, R. y otros. (2016). Constitucionalismo, garantismo y democracia. Buenos Aires: Ad Hoc; Constitucionalismo progresista. Retos y perspectivas. México: UNAM; Gargarella, R. (2015). La sala de máquinas de la Constitución. Buenos Aires: Katz Editores; Gargarella, R y Courtis, C. (2009). El nuevo constitucionalismo latinoamericano. Promesas e interrogantes. Santiago de Chile: Cepal; de Waldrom, J. (1998). Judicial review and the conditions of Democracy. The Jornal of Political Philosophy, 6 (pp. 335-355); del mismo autor (2005). Derechos y desacuerdos. Madrid: Marcial Pons; de Dworkin, R. (1995). Constitucionalism and Democracy. European Journal of Philosophy, 3 (pp. 2-11); (2006); Is Democracy posible here. New Jersey: Princeton: University Press; de Viciano Pastor R. y Martínez Dalmau, R. (2010). ¿Se puede hablar de un constitucionalismo latinoamericano como corriente doctrinal sistematizada? España: Universidad de Valencia, ponencia presentada en el VIII Congreso Internacional de Derecho Constitucional, UNAM, recuperada de www.juridica.mx; de Bayon, J. C. (1998). Derechos, Democracia y Constitución. Discusiones. No 1 (pp. 65-94 Bahía Blanca, Argentina; de Honneth, A. (1997). La lucha por el reconocimiento. Por una gramática moral de los conflictos sociales. Crítica. Barcelona; el clásico de Rawls, J. (1997). Liberalismo político. Crítica. Barcelona, etc. 
En este sentido, Pedro Pablo Serna trae a colación la opinión de Adela Cortina, quien expresa que la democracia en el sentido habermasiano, ha procurado:

(...) socializar el poder, democratizarlo, buscando una democracia mayor. Esta profundización de la democracia, que tiene efectos a nivel político y social, ha venido proponiéndose desde diferentes frentes y de manera específica desde el liberalismo político. Según Cortina, la idea de democracia radical es presentada originalmente por J. Habermas y es, según él, propia de una izquierda socialista no comunista. Tal democracia (...) debería entenderse como una democracia participativa, en la que los ciudadanos ejercen su autonomía en solidaridad, con lo cual habríamos hallado en esta propuesta el modelo de procedimiento socialista buscado, porque además de pretender ser aplicado al caso de sociedades complejas y no ya a la polis griega o a comunidades cuya unidad de objetivos hoy trataríamos de recrear. Tal idea de participación viene abonada por dos de las dimensiones del enfoque habermasiano: la ética discursiva y la teoría de la sociedad (Cortina, 1994, p. 931) (...) (Serna: 2008, pp. 274-275).

Como es sabido Habermas confronta dos proyectos democráticos, el liberal, cuya función consistiría en legitimar básicamente el ejercicio del poder político. En este modelo, el poder para gobernar se asume por vía electoral, y quienes gobiernen deben justificar ante los ciudadanos y el Parlamento, el uso que hacen de ese poder. El otro modelo, es el republicano, en donde la democracia tiene una función especial, radicalmente fuerte, que es precisamente la función de constituir una sociedad como comunidad política, y mantener vivo en forma constante ese acto fundacional (Habermas, 2008, pp. 375-376).

En el marco estrictamente político de la generación y distribución del poder se distancian también ambos modelos, como se puede apreciar. Este concepto habermesiano fuerte que aparece en el modelo republicano, dirigido a la constitución de una comunidad política y la mantención tanto en la memoria y en la posibilidad de un ejercicio político comunitario permanente, se genera y legitima desde ese acto fundacional, y es sin duda lo que se denomina "poder constituyente", que como se verá, tiene especiales particularidades.

Se distingue usualmente la noción de "poder constituyente", de aquella de "poder constituido". Este último es aquel poder, constitucional y legalmente estatuido y regulado a partir de una constitución, y particularmente, en opinión - por ejemplo- de Riccardo Guastini, desde la primera constitución del Estado. El poder constituyente, en su opinión, el que instaura la primera constitución (2001, p. 40). En esta visión positivista, el poder constituyente despejado de ideología, dice el autor, no es fundamento axiológico de la Constitución, es el hecho que da 
nacimiento a la primera constitución, pero no sobrevive, sino que desaparece con ella y en ella.

Por el contrario, en la visión del modelo de democracia republicana, antesala del proyecto de democracia radical que ensaya Habermas, el poder constituyente no fenece, permanecería vivo y siempre activo.

No obstante, si bien este tema que revela tener suma importancia filosófica, conceptual y jurídica, no es naturalmente lo único que caracteriza - desde la óptica que se viene aportando- al modelo de democracia radical habermasiano, que como se anotara, tendría su matriz en el modelo de democracia republicana y se profundiza y distancia a la vez, de aquel otro de democracia liberal.

A partir de estos aspectos generales, que, además, en Habermas, como bien expresan Mejía Quintana y Jiménez (2005, p. 17), la idea se constituye con base en un modelo sociológico de política deliberativa de doble vía, que en mucho lo acerca a Luhmann. Las posturas críticas post-habermasianas que se concretan en la tercera generación de la escuela de Frankfurt, profundizan el modelo inicial, con la intención de recuperar el contenido utópico (Offe, Wellmer, Dubiel y Honneth). De tal forma, la idea de "democracia radical" es profundizada hasta donde sus condiciones históricas y sociales lo permiten, tratando de dar respuesta incluso al interrogante, de si esta cuestión democrática es solo propia del pensamiento marxista incluso heterodoxo y hasta qué punto la reflexión postsocialista puede asimilarla como propia, sin concesiones al pensamiento burgués liberal (Mejía Quintana, Jiménez, 2005, p. 17).

En este contexto, Serna expresa que para Chantal Mouffe, la tarea principal de la democracia moderna, consiste en "transformar el antagonismo en agonismo (relación entre adversarios)", o de otra manera, como expresa el autor citando también nuevamente a Mouffe y a Atilli, que en tanto la democracia moderna es el orden legitimador del conflicto, se convierte en el espacio adecuado para el disenso. Es la lucha de adversarios, no de enemigos. El orden propuesto por la democracia debe ser el orden legitimador del conflicto “(...) la gran tarea en una democracia moderna pluralista es tratar de encontrar las instituciones, las prácticas o los discursos que permitan transformar el antagonismo en agonismo" (Atilli, 1996, p. 143). Aparece así la posibilidad de la existencia del pluralismo, como elemento clave en el desarrollo de mayores niveles de democracia (Serna, 2008, p. 275).

Serna convoca también la opinión de Nancy Fraser (Serna, 2009, p. 275), quien argumenta que el concepto de democracia radical resulta aún ambiguo, en la medida que ha sido trabajado solo en el plano político cultural, por lo que debe ser llevado al plano de la economía política, en donde deben vincularse "política del reconocimiento" y "política social de la redistribución", para lograr un sentido más 
pleno. Para establecer este vínculo, deberán superarse los impedimentos de la realización de la democracia radical, que son "la desigualdad social" y "el irrespeto a la diferencia" que no es otra cosa para la referida autora, que la reubicación de la política cultural en sintonía con la política social, que permitirá recolocar las exigencias propias del reconocimiento con las exigencias de la redistribución.

De tal manera, como explica Serna, en opinión de Fraser, es necesario el reconocimiento de formas públicas de multiculturalismo, para poder llegar al reconocimiento de una democracia más real y expresa: (...) es necesario tener en cuenta las diferencias sociales que generan desigualdad social y desarrollar una visión amplia y antiesencialista, que permita el reconocimiento de distintas expresiones, modos de ser y de sentir al interior de las naciones (...) (Serna, 2009, p. 275).

No obstante, expresa el autor, es notoria la dificultad para que, en las naciones empobrecidas, se presente una ciudadanía que sea realmente abierta, crítica y deliberativa, a la que se pueda llamar, tal como expresa Mouffe "agonística", "que no sólo es receptora de bienes y servicios por parte del Estado sino activa y, por lo tanto, emancipatoria o reivindicativa (...). Bajo la consigna de que a mayores niveles de democracia (...) por lo tanto mayores niveles de poder para la ciudadanía (...)" (Serna, 2008, p. 279).

Por su parte, Acosta, ya citado, entiende que democracia resulta ser: “(...) un orden de convivencia en que todos pueden vivir, no porque el crimen no sea posible, sino porque no esté legitimado (...)" (2008, p. 78). Expresa en concordancia con Lechner, que este orden de convivencia ha sido caracterizado como "la conflictiva y nunca acabada construcción del orden deseado". Esta conflictiva y nunca acabada construcción del orden democrático deseado, es así: “(...) la conflictiva y nunca acabada constitución del ser humano (persona, comunidad, sociedad, humanidad) como sujeto (...)". De esta manera, la construcción de la democracia, opera en estricta reciprocidad con la construcción del sujeto - aspecto que se ha analizado líneas antes- potenciándose en términos de posibilidad histórica y marcándose límites en términos de plenitud y, por ende, de posibilidad utópica. Esto conlleva una paradoja: la plenitud del ser humano, operaría más allá de cualquier límite, no obstante, la inserción en un orden de convivencia, implica el acotamiento de la plenitud del sujeto, a los límites que impone ese orden de convivencia (Acosta, 2008, p. 79).

Vale la pena precisar que en la tónica del autor, si la democracia es un orden de convivencia en que el crimen no es posible o siendo posible no se encuentra legitimado, interesa precisamente destacar que cobran especial interés aquellos crímenes que se cometen o legitiman en nombre de la democracia, por lo que resulta absolutamente imprescindible que en la construcción de ese orden de 
convivencia, no se encuentren nunca legitimados los crímenes que se cometen en nombre de aquella (Acosta, 2008, pp. 79-80).

Por otro lado, es claro que ese orden de convivencia que tiene esa capacidad de invalidar el crimen por falta de legitimación y más aún aquel que se comete en nombre del orden democrático, implica la aceptación de procedimientos que hacen a la democracia como forma de gobierno, en cuya caso implica la admisión de una racionalidad comunicativa, tendiente a la construcción de la democracia como un orden inclusivo de racionalidad participativa para todos (todas-todos), sin exclusiones (Acosta, 2008, p. 80).

En la propuesta en curso, y aun reconociendo la posibilidad de ciertas ambigüedades que el modelo de "democracia radical" pueda presentar en sus aspectos más generales, es claramente el que se postula en este texto, como forma superadora del concepto de democracia liberal que prioriza el contenido político formal, o, dicho de otra manera, forma ésta que reduce lo democrático a la forma jurídicapolítica de gobierno.

Se postula concomitantemente, entonces, una posibilidad real de aplicación del modelo de democracia radical, para las formaciones sociales latinoamericanas, en la mayor escala posible.

Ese modelo aún en formación, en construcción y segura superación como "orden deseado", se asienta, además, en tres ideas sustantivas que nítidamente pueden inferirse y se señalan a continuación:

a) El reconocimiento de que el rol social que juega el derecho en el marco de un modelo radical aplicable a las democracias latinoamericanas contemporáneas depende de una relación de poder, es decir, de una relación de fuerzas en el marco del conflicto social (Cárcova, 2007, p. 140), pues el escenario en que se desenvuelve la democracia radical es como se viera, el del conflicto adversarial entre agonistas, sujetos humanos y grupos humanos.

En tal sentido es predicable, entonces, que en este modelo democrático se considera legítimo el conflicto, ya que precisamente el conflicto posibilita en su dinámica, que se organicen individuos y grupos y se especifiquen los controles que corresponden a la ciudadanía (Serna, 2008, p. 280), y particularmente de los grupos que se encuentren en situación de vulnerabilidad y eventual discriminación.

b) El modelo de democracia radical, aplicable a las democracias latinoamericanas, debe necesariamente partir y, además, constituirse como realización plena de un régimen de derechos humanos (Hinkelammert, 1990, p. 133), que, además, de propiciar el aspecto de la dimensión jurídico-política del gobierno, potencie 
sus dimensiones sociales, económicas, distributivas, culturales y ecológicas y finalmente.

c) El modelo democrático radical, pensado para las democracias latinoamericanas, debe ser claramente un ámbito de reconocimiento del pluralismo y de la heterogeneidad, sin ningún tipo de exclusiones.

Resta abordar brevemente un tema de naturaleza formal colindante a lo que se ha venido exponiendo y es el relativo al posible carácter universal o no de los derechos humanos.

Es claro que a partir de que se sostiene categorialmente la postulación y finalmente la lucha por la concreción de un "humanismo crítico nuestro-americano", se debe concluir que resulta ser ésta, una discusión que carece de sentido. El universalismo es sólo un particularismo triunfante que deviene hegemónico (Ernesto Laclau). El presente Latinoamericano - un siglo XXI forzosamente globalizado que desborda en su complejidad - quizá ha tenido la ventaja (una de las pocas) de ser un escenario para que se puedan observar las diferencias culturales, de tradición, sociales, históricas, políticas, económicas, e "nuestra América", frente a otros horizontes culturales y lograr que se visualice el orden de su siempre renovada dependencia.

Si bien existen denominadores comunes atinentes a "lo humano universal", el acaecimiento de "lo humano" en nuestro "horizonte cultural", es por esas mismas razones, intransferible. Entenderlo de otra manera sería claramente no homologable.

Podría concederse, que puede existir - teóricamente- una universalización en torno a los llamados derechos humanos de primera generación, pero pretender una universalización de aquellos que, en la pragmática de los derechos humanos, se entienden como de segunda y ulteriores generaciones, resulta poco aceptable y realmente cuestionable.

\section{La situación de Uruguay. Breves conclusiones}

Latinoamérica, la región más cercana (solo para no mirar más lejos), Uruguay país inmerso en ella, viven hoy en el marco de una notoria y creciente "complejidad" propia también del marco económico y geopolítico en que les ha ido en suerte vivir en este presente mundo-global, cuestión - perversa- que ya se ha analizado.

Por cierto, que más allá de pugnar por un "humanismo crítico nuestro-americano" resulta una tarea difícil hacer generalizaciones en este contexto, por las 
peculiaridades que presentan cada una de las formaciones sociales que integran el continente, por más que existen rasgos identificativos y compartidos que describen el referido sentido de "complejidad" y que por cierto va mucho más allá de pensar que las sociedades latinoamericanas resultan acaso ser tan solo complicadas.

De hecho, pues, toda "sociedad compleja" se caracteriza básicamente por una diferenciación funcional nítida entre los sistemas y subsistemas parciales que la componen que apuntan a una creciente autonomía, una radical división del trabajo mediante la especialización y capitalización del conocimiento por sujetos y grupos sociales, una diversificación económica sujeta a las turbulencias globales, junto con el surgimiento de nuevas formas de institucionalización jurídico-políticas y un acentuado proceso comunicacional (3).

En este plano existe también una cuestión de consideración previa, que consiste en la aparente y por qué no común percepción, de que el revitalizado tema de los derechos humanos, puede ser parte necesaria de una agenda que se nutre únicamente desde los espacios del poder político.

Se postula en este trabajo que no es exclusivamente así. Veamos.

Sí lo es, en tanto desde el poder político debe existir un compromiso radical con los derechos humanos desde el marco de una Democracia, también radical, en construcción. Pero existe otra perspectiva necesaria que se erige por fuera del poder político institucionalizado en el marco estatal.

En efecto, siempre debe presentarse un fuerte compromiso de reclamo vigilante desde la ciudadanía - tanto desde sujetos, grupos y movimientos socialescomo parte de su propia autoconstrucción ciudadana, en la medida que la necesaria tensión entre lo institucional y lo ciudadano, a veces conflictiva, contribuye siempre al mantenimiento vigente, a la continuidad, a la reivindicación cuando sea necesaria y a la proyección deseada en términos evolutivos de tales derechos. Fundamentalmente, porque ellos son necesariamente consecuentes e imprescindibles para el proyecto de emancipación de cualquier tipo de subordinación o dependencia, tanto de los sujetos individuales como colectivos en "nuestra América" (Meliante, 2017).

El eje binario democracia radical-derechos humanos, entonces, se focaliza y percibe como sustentable y necesario en la complejidad Latinoamericana, como

(3) La opinión, sin duda esquemáticamente expuesta, recoge las posiciones de Luhmann y Habermas sobre teoría de sistemas y otros tópicos, que se publicara en el conocido texto "Discusión: Teoría sobre los sistemas sociales", Barral, 1975. 
forma de contribución a la estabilidad socio-política interna de sus formaciones sociales, y a su inveterada necesidad de emancipación, que se transmuta históricamente en forma permanente hacia lo exógeno.

En los países del continente que sufren - en mayor o menor grado- las consecuencias de este complejo proceso globalizador, con el avance reciclado y ostentoso de las derechas extremas neoneoliberales, se piensa que habrá de constituir una terapéutica beneficiosa, retomar en forma gradual, lenta pero segura, el protagonismo político democrático y mediador del Estado en su trama interna, para posibilitar de esa forma la reapropiación de la participación por parte de los sectores sociales que resultaron debilitados por la sacudida globalizante, en la toma de decisiones político-económicas y sociales, reales.

En este contexto, la profundización democrática hacia una democracia radical, conciliación de lo tópico y lo utópico necesario como se ha expresado, debe facilitar la "participación popular en todos los asuntos de interés público, habilitando mediante los mecanismos institucionales la "realización autogestionaria de la política", debe implementar " una lucha frontal contra la corrupción", debe hacer efectiva "una clara intervención en la gestión económica y financiera cuando tenga contenido estratégico a nivel nacional", debe propiciar "un aseguramiento de la correcta distribución de recursos" y, además, sin claudicaciones, debe asegurar "una custodia permanente de las libertades individuales, junto con la eliminación absoluta de cualquier tipo de discriminación y exclusión" (Cárcova, 2007).

En lo que dice relación con Uruguay, agotado que resultó el proceso dictatorial por la lucha político-ciudadana y por el peso de su total inconsistencia histórica, durante mucho tiempo y en muchos aspectos, el desarrollo pragmático de los programas de derechos humanos, no fue o no pudo ser desarrollado adecuadamente. Costó mucho y aún sigue costando mucho.

El Estado uruguayo tuvo serias dificultades para desarrollar políticas sociales adecuadas, que transitaran por una hermenéutica de la pobreza, con la consigna de que la pobreza es una vivencia, un acontecer existencial y por eso no constituye un aspecto meramente cuantificable, pues requiere un análisis político, uno económico, así como uno jurídico, pero también uno que conlleve una perspectiva comunicacional. Porque precisamente por eso, por ser un acontecer existencial, una vivencia, debe ser cabalmente comprendida, lo que no puede lograrse con exclusión de esa perspectiva.

El Estado uruguayo tampoco ha podido propiciar políticas públicas que contemplen decididamente un cambio posible en el ámbito carcelario y que velen adecuadamente e intercedan, además, para evitar que se afecten todos aquellos aspectos inherentes a la dignidad de quienes están privados de libertad. De no 
hacerse continúan resultando algo mítico, los programas de acción plasmados con esa finalidad en la propia carta constitucional. En este aspecto, aún hoy, poco se ha logrado.

Tampoco, pese a que han transcurrido prácticamente cuarenta y cinco años de la nefasta perpetración dictatorial, aún no se han cerrado las heridas que provocaron años de inusitada prepotencia y violación de los más elementales derechos cualquiera sea su naturaleza jurídica y su fundamento- y que fueran avasallados en forma inmisericorde por la dictadura cívico-militar que recaló en Uruguay en los años setenta del siglo pasado.

Si bien es cierto que se han revalorizado los derechos humanos en muchos aspectos, sobre todo en materia sexual, familiar de género y diversidad, así como también en otras esferas sentidas como privadas o connaturales a la misma definición de la personalidad humana, ello no ha bastado ni bastará.

Es posible, también, que a nivel social se detecten señales que puedan ser interpretadas como demandas de democratización creciente y más profunda, aunque no sean explicitadas nominalmente como tales, y que se perciba una constante necesidad de prevenir algún desborde autoritario de poder, explícito o implícito, sobre todo cuando viene del poder público.

Tales aspectos se enmarcan sin mucha dificultad en el eje binario ya señalado (democracia radical - derechos humanos) y seguramente pueden asociarse, sin mucho esfuerzo, a formas relativamente primarias de radicalización democrática como un horizonte deseado.

\section{Bibliografía}

Acosta, Y. (2005). Sujeto y democratización en el contexto de la globalización. Perspectivas críticas desde América latina. Universidad de la República, Montevideo: Nordan-Comunidad.

Acosta, Y. (2008). Filosofía Latinoamericana y Democracia en clave de Derechos Humanos. Universidad de la República. Montevideo: Nordan-Comunidad.

Acosta, Y. (2015). La filosofía Latinoamericana es un humanismo. En Y. Acosta; W. Ansaldi; V. Giordano y L. Soler (coord.), América Latina Piensa América Latina (pp. 117, 132). Ciudad autónoma de Buenos Aires: Consejo Latinoamericano de Ciencias Sociales.

Assef, L. (1998). La Teoría Crítica en la Argentina. Doxa. Cuadernos de Filosofía del Derecho, № 21, Vol. II (pp. 21-32). 
Atilli, A. (1996). Pluralismo agonista: la teoría ante la política. Entrevista con Chantal Mouffe. Revista internacional de filosofía política, No 8 (pp. 139-150). ISSN 1132-9432.

Bauman, Z. (2004). Modernidad líquida. $3^{\mathrm{a}}$ ed. Buenos Aires: Fondo de cultura económica.

Beck, U. (1998). ¿Qué es la globalización? Falacias del globalismo, respuestas a la globalización. Barcelona: Paidós.

Bruchera, O. (1986). Las décadas infames. Montevideo: Linardi y Risso.

Cárcova, C. M. (2007). Las teorías pospositivistas. Buenos Aires: Lexis Nexis.

Cobos J. (1995). América Latina. Madrid: Acento Editorial.

De Souza Santos, B. (1989). La transición postmoderna. Derecho y Política. Doxa. Cuadernos de Filosofía del Derecho, № 6 (pp. 223-263).

Fernández Oliva, M (2014). Notas sobre el origen y desarrollo del derecho a la intimidad en la familia jurídica del Common Law. Investigación y Docencia, № 48 . Rosario: Facultad de Derecho de la Universidad de Rosario.

Guastini, R. (2001). Estudios de Teoría Constitucional. México: Fontamara.

Gross Espiell, H. (2003). Una visión latinoamericana de la Carta de los Derechos Fundamentales. UNESCO, Cátedra Unesco de Derechos Humanos. Montevideo: Universidad de la República.

Habermas, J. (1998). Debate sobre el liberalismo. Barcelona: Paidós.

Habermas, J. (2008). Facticidad y validez. Madrid: Trotta.

Hinkelammert, F. J. (1990). Democracia y totalitarismo. $2^{\text {a }}$ ed. San José: DEI.

Luhmann, N. y Habermas, H. (1975). Discusión: Teoría sobre los sistemas sociales. Barcelona: Barral.

Maurel-Indart, H. (2014). Sobre el plagio. Buenos Aires: Fondo de Cultura Económica.

Mejía Quintana, O. y Jiménez, C. (2005). Nuevas teorías de la Democracia. De la Democracia formal a la democracia deliberativa. Colombia Internacional, № 62, julio-diciembre (pp. 12-31). Recuperado de http://www.scielo.org.co/scielo.php?pid=S0121-56122005000200002\&script=sci_abstract\&tlng=es 
Meliante Garcé, L. (2006). Derechos Humanos y Derecho Privado en la sociedad uruguaya contemporánea. Revista Crítica de Derecho Privado, № 3. Montevideo: Carlos Álvarez editor.

Meliante Garcé, L. (2014). La crítica jurídica latinoamericana en sentido estricto: de la invisibilidad a su consideración en la doctrina nacional. Revista de la Facultad de Derecho, No 36. Montevideo: Universidad de la República.

Meliante Garcé, L. (2017). Derecho, comunidades interpretativas y movimientos sociales: una fisura en la ortodoxia. Revista Anales, No 47 (pp. 833-863). Buenos Aires: La Ley.

Meliante Garcé, L. (2018). Latinoamérica en la región: "sociedad liquida", decisión judicial y política Un conflicto agudo, apenas disimulado. Revista Anales, № 48. Recuperado de https://revistas.unlp.edu.ar/RevistaAnalesJursoc/article/ view/5572

Serna, P. (2008). Democracia radical y ciudadanía. Revista Eidos, № 9. Colombia. ISSN 1693-885.

Fecha de recepción: 23-03-2019 Fecha de aceptación: 29-09-2019 